\title{
Cardinal numerals in rural sign languages: Approaching cross-modal typology
}

\author{
ULRIKE ZESHAN, CESAR ERNESTO ESCOBEDO DELGADO, \\ HASAN DIKYUVA, SIBAJI PANDA, and CONNIE DE VOS
}

\begin{abstract}
This article presents data on cardinal numerals in three sign languages from small-scale communities with hereditary deafness. The unusual features found in these data considerably extend the known range of typological variety across sign languages. Some features, such as non-decimal numeral bases, are unattested in sign languages, but familiar from spoken languages, while others, such as subtractive sub-systems, are rare in sign and speech. We conclude that for a complete typological appraisal of a domain, an approach to cross-modal typology, which includes a typologically diverse range of sign languages in addition to spoken languages, is both instructive and feasible.
\end{abstract}

Keywords: cardinal numerals, morphology, numeral bases, numerals, rural sign languages, sign languages

\section{Introduction}

This article discusses primary data on cardinal numerals from three sign languages in small-scale rural communities in Turkey, India, and Mexico. Research on such "rural sign languages" is a very recent undertaking, and here we aim to contribute toward what is known about the typology of signed and spoken languages. Sections 1.1 and 1.2 introduce the phenomenon of rural sign languages as compared to the better-documented sign languages of urban deaf communities, as well as presenting an overview of what we know about cardinal numerals in urban sign languages, as compared to spoken languages. Section 2 details the sociolinguistic setting of the target languages, followed by the data analysis in Sections 3 and 4. Importantly, our research results clearly illustrate the value and feasibility of a cross-modal typology of cardinal numerals, covering a variety of both signed and spoken languages. These implications are explored in Section 5. 


\subsection{Urban sign languages and rural sign languages}

Since its inception in the 1960s and 1970s, research on sign languages has focused on communities of deaf people who constitute linguistic and cultural minorities within the larger hearing, non-signing society (e.g., van Cleve 1987, Lucas (ed.) 2001). Since a critical mass of deaf people is needed to give rise to a sign language, these linguistic and cultural minorities are most commonly associated with larger, often urban, populations. They typically include dedicated institutions and infrastructures such as schools for the deaf, deaf associations, etc. They are also characterised by significant communication barriers for deaf individuals, and collective experiences of exclusion and disadvantage vis-à-vis the hearing majority of non-signers, but also a strong sense of "deaf community" for many deaf individuals (Lane 1992, Padden \& Humphries 2006).

The sign languages discussed in this article have radically different sociolinguistic and cultural parameters, and research on these languages and their unique setting is very recent (e.g., Zeshan 2010, Meir et al. 2010). They exist in small rural communities with a high incidence of hereditary deafness over several generations, which gives rise to indigenous sign languages separately and independently of urban deaf communities (Groce 1985, Lane et al. 2000). For simplicity's sake, these languages are collectively called "rural sign languages" here, although this can include cases other than a prototypical single "deaf village" (cf. Section 2). By contrast with urban deaf communities, rural sign language communities are generally characterised by the following features: ${ }^{1}$

(i) there is a high incidence of hereditary deafness over several generations;

(ii) the sign language is used on a daily basis by the great majority of hearing people in the community;

(iii) consequently, there is a much higher degree of integration between deaf and hearing people, and communication barriers are of lesser or no importance in the daily lives of deaf people;

(iv) there are usually no dedicated institutions for deaf people, e.g., schools or clubs for the deaf.

A substantial number of rural sign languages have been identified, mostly located in developing countries. Over the past decade, sign language linguists have started to document the structures of these sign languages (e.g., Sandler et al. 2005, Nyst 2007, Marsaja 2008, Perniss \& Zeshan 2008, Nonaka 2009, de Vos 2012), and it has become clear that rural sign languages can have linguistic structures that differ radically from urban sign languages. The data discussed in this article add to this emerging picture.

1. This is a simplified account, as we also find important differences between rural sign language communities (cf. the descriptions of field sites in Section 2). 
All known rural sign languages are endangered, usually because of pressure from larger urban sign languages. While the vitality of some urban sign languages is also threatened in the long term, for instance through medical advances resulting in a lower incidence of deafness in industrialised countries, most rural sign languages are in immediate danger of becoming extinct without ever having been properly documented (Zeshan \& de Vos (eds.) 2012).

\subsection{Numerals in signed and spoken languages}

Across spoken languages, numerals are among the most widely documented linguistic structures. Both in individual languages and in typological surveys of various sizes, there is a wealth of available data on numeral systems in spoken languages. Typological or comparative studies that discuss numerals include works such as Greenberg (1978), Hurford (1975, 1987), Comrie (1997, 2005a), and Gil (2005). Substantial samples of languages have been used to look at numerals across spoken languages, e.g., work reported in Comrie (2005a) with 196 languages, Barriga Puente (1998) with 344 languages, and Hanke (2010) with 281 languages. Across spoken languages, cardinal numerals are particularly welldocumented.

The same level of documentation is currently not available for sign languages. $^{2}$ Although the main focus of this article is on little-known sign languages in small rural communities, it is useful to begin with some comments on the structure of numeral systems in various urban sign languages. No systematic typological survey of numeral systems in sign languages has been undertaken yet, but information on numerals, in particular cardinal numerals, is available from various sources. Numeral signs feature in many sign language dictionaries, both printed (e.g., Suwanarat et al.1990, Wallin et al. 2006, Tang 2007) and online (e.g., Finnish Association of the Deaf 2003, Johnston et al. 2005, Nederlands Gebarencentrum 2010), and numerals are generally included in sign language teaching materials where such materials exist (e.g., BakerShenk \& Cokely 1991, Dikyuva \& Zeshan 2008). In-depth linguistic studies on aspects of numeral systems in sign languages are much rarer and currently limited to the better-documented sign languages, mostly in industrialised countries (e.g., Fischer 1996, Fuentes \& Tolchinsky 2004, Fuentes et al. 2010, Ichida 2005, Mori 2005, Ktejik 2013, Skinner 2007, McKee et al. 2011).

Despite this paucity, surveying these resources reveals quite clearly which linguistic structures are common across various urban sign languages around the world, and which are currently unattested in the sign language research

2. A current project in sign language typology at the International Institute for Sign Languages and Deaf Studies, University of Central Lancashire, is aiming to fill this gap. Detailed results are not yet available, but the data from 30 sign languages collected for this on-going project has informed the background discussion here. 
literature. Before we move on to describing the data from rural sign languages, it is useful to summarise common structures found in urban sign languages. These structures are then compared with the findings from primary data in rural sign languages (Sections 3 and 4).

A common factor in the classification of numeral systems is the notion of "numeral bases". For the purpose of this article, numeral bases are conceptualised as those numerals on the basis of which other numerals are constructed; that is, in the sense of Comrie (2005b: 207), a base is "that numerical value to which various arithmetical operations are applied". Following Hanke (2010: 68-69), we distinguish here between additive bases (numeral bases to which other numerals are added) and multiplicative bases (numeral bases which are subject to multiplication). ${ }^{3}$

Across urban sign languages, as in the great majority of spoken languages, 10 is the most common numeral base. In fact, surveying available materials on urban sign languages has revealed virtually no incidents of sign languages with numeral bases larger than $10 .{ }^{4}$ The predominance of base-10 numeral systems is paralleled in spoken languages, and there is an evident cognitive link between base-10 numeral systems and the anatomy of the human hands, because "verbal counting has very often, if not always, its origin in physical, or rather manual counting" (Hanke 2010: 72). Nevertheless, bases other than 10 do occur with some regularity across spoken languages, e.g., systems involving the numeral base 20 (vigesimal systems). The sample of 196 spoken languages in Comrie (2005a) includes $10 \%$ of languages with vigesimal systems. For sign languages, such data have so far been unavailable, and the rural sign languages discussed here are the first documented cases of numeral bases higher than 10 in any sign language.

Research across spoken languages has shown that the main strategies for constructing numerals are the additive and multiplicative strategies. These are by far the most common arithmetic operations used to construct numerals. Examples (1a) and (1b) instantiate these two strategies. Both use the numerals 4 and 20, but apply a different arithmetic operation. Moreover, the operation is overtly expressed in German (using und), but both multiplication and addition are implicit in the French example, with no overt marking of the arithmetic operation.

3. For some alternative definitions, see, e.g., Greenberg (1978), Hurford (1975), von Mengden (2010).

4. It has been argued that some sign languages may have base-5 numerals; cf. Skinner (2007) for British Sign Language and Lanesman (2012) for Algerian Jewish Sign Language. These analyses can be contested, but doing so is outside the scope of this article. 


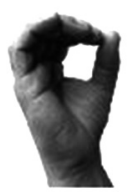

0

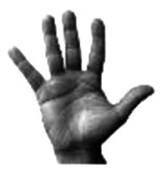

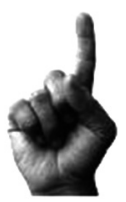

1

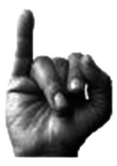

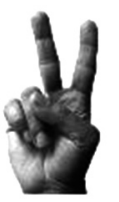

2

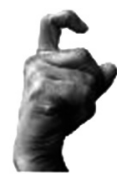

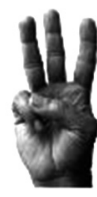

3

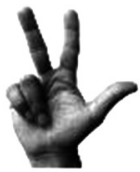

8

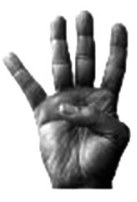

4

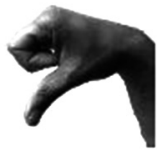

Figure 1. Numerals 0 to 9 in IPSL (north-western India)

(1)
a. German
vier-und-zwanzig
$4+20$
' 24 '
b. French
quatre-vingt-dix
$4(\times) 20(+) 10$
' 90 '

Sign languages also make ample use of both additive and multiplicative strategies. For numerals 1 to 10 , there is a split between one-handed and two-handed numerals across documented sign languages. One-handed systems use a different shape configuration of the hand ("handshape") for each numeral. Figure 1 shows an example from a north-western Indian dialect of IndoPakistani Sign Language (IPSL). ${ }^{5}$ Two-handed systems may simply use the corresponding number of extended fingers for numerals 1 to 10 , for example, extending five fingers of one hand and two fingers on the other hand to express the numeral ' 7 '.

For higher numerals, sign languages, like spoken languages, need to combine various numeral signs and strategies. If an additive strategy is used, the common pattern across urban sign languages for constructing numerals above 10 is to sign the highest numeral first, followed by each successively smaller numeral, without overtly expressing the additive relationship. Figure 2 illustrates this pattern with examples from Ugandan Sign Language, British Sign Language (BSL), and Turkish Sign Language (Türk Işaret Dili, TID).

5. Many sign languages have dialectal variation with respect to the form of cardinal numerals, though the way in which numerals are constructed is usually not subject to such variation, or at least not to the same extent. In this dialect, the number '10' uses a different pattern with internal finger movement, derived from signing ' 1 ' followed by ' 0 '. 


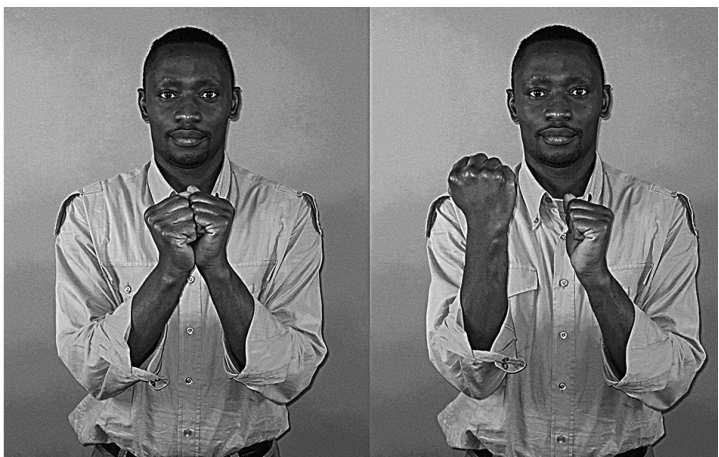

Ugandan SL ‘ 15 ’ (10+5)

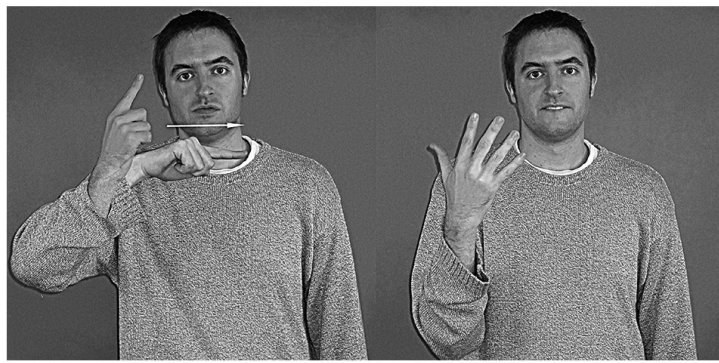

BSL ‘105’ (100+5)

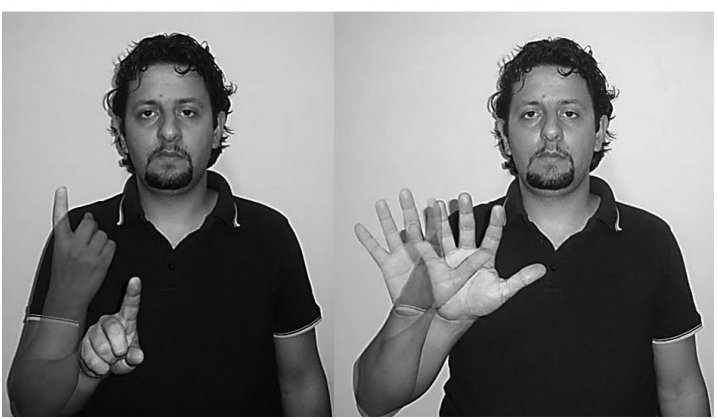

TiD ‘ 1,050 ’ $(1,000+50)$

Figure 2. Additive numerals in sign languages

The multiplicative strategy is very common across sign languages to create numerals that are multiples of 10 , that is, tens, hundreds, thousands, etc. In particular, many sign languages use a simultaneous morphological process to create higher magnitude numerals. In this process, numerals from 1 to 9 are combined simultaneously with a hand movement that indicates, for instance, 


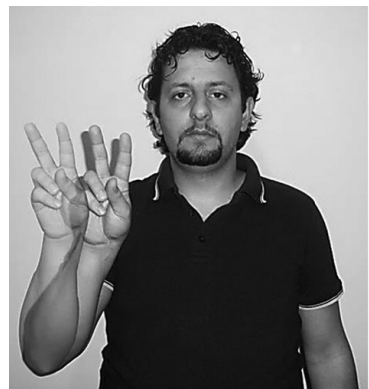

' 20 '

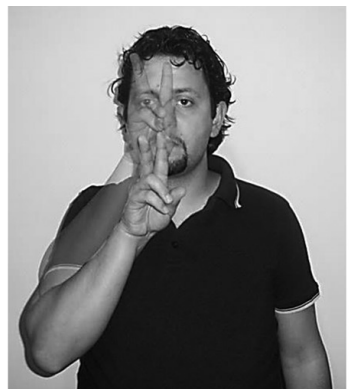

'200'

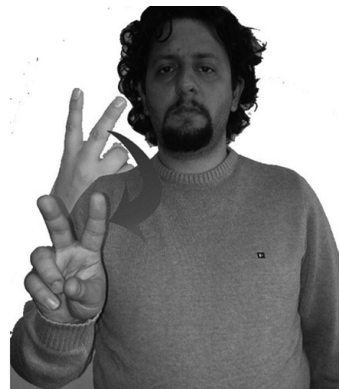

'2,000'

Figure 3. Numeral incorporation in TID

hundreds or thousands. Figure 3 shows examples of such numeral signs from TID. Each of the numerals has the '2'-handshape combined with a different movement pattern ('two tens', 'two hundreds', and 'two thousands').

This type of simultaneous morphology has been documented across many sign languages, often using the term "numeral incorporation" (e.g., Chinchor 1982, Massone \& Johnson 1991, Zeshan 2000: 73), and the same process applies to other quantifiable concepts such as time units ('two years', 'two hours'). Some sign languages even incorporate interrogative morphemes in this way ('how many years', 'how many hundreds'), e.g., Chinese Sign Language (Yang (forthcoming)). While this kind of simultaneous morphology has no direct counterpart in spoken languages, it is akin to sequential combinations such as four-teen and four-ty in English. The morphemes -teen and -ty are equivalent to the movement patterns in Figure 3. Simultaneous morphology in numerals is an interesting addition to the typology of numerals across languages.

In spoken languages, subtractive strategies are far less common than additive and multiplicative strategies, and are typically restricted. Subtractive numerals occur most often where the values of ' -1 ' and ' -2 ' are involved, and a number of spoken languages in the Americas and Africa have such numerals (cf. Williamson (ed.) 1973 on Benue-Congo and Barriga Puente 1998). Barriga Puente's sample of 344 languages from the Americas includes three instances of subtractive systems, one of them Central Wintun: ketel '1', cema-ketel '9', cema '10' (Barriga Puente 1998: 81). Subtractive numerals also occur in Athapascan languages (Hymes 1955: 30):

The conception of 9 as one less than ten, or as approaching ten, is a frequent Athapascan feature [...]. Often, however, its meaning seems to have been descriptive of the position of the fingers in counting - 'one bent down', etc.

The repeated reference to the human hands and fingers that we see in the description of spoken language numerals creates an intriguing link to sign lan- 
guages, where the hands and fingers are actually present. It is all the more interesting to note that subtractive numerals have previously been unattested in sign languages and are documented in this article for the first time.

Sign languages share one further strategy which can be called a "digital strategy", as it involves signing individual digits, in the order in which they appear in writing, e.g., ONE TWO '12' and TWO FIVE ZERO '250' from the Indian varieties of IPSL, called "Indian Sign Language" in AYJNIHH \& Zeshan (2001). ${ }^{6}$ For large numerals, IPSL has separate lexical signs for THOUSAND, LAKH ('100,000'), and CRORE ('10,000,000'). Ugandan Sign Language uses a similar digital system for numerals between 20 and 999, with a different set of handshapes from 1 to 9 (Wallin et al. 2006).

To summarise, common features of cardinal numeral systems in urban sign languages include base-10 numerals, additive and digital strategies, and simultaneous morphology as a multiplicative strategy. By contrast, as Sections 3 and 4 demonstrate, the rural sign languages investigated here use a very different array of structures in their systems of cardinal numerals, some of which have never been documented before in any sign language. Comparing our available data from both urban and rural sign languages with data from spoken languages leads to interesting conclusions when we consider the notion of cross-modal typology in Section 5.

\section{Methodology: Languages, field sites, and data}

\subsection{Chican Sign Language (Yucatán, Mexico)}

The village of Chican is situated in the municipality of Tixméhuac on the Yucatán Peninsula and has about 720 inhabitants. Currently, there are 17 deaf people in the village, both male and female, between the ages of 7 and 78 (Escobedo Delgado 2010). Chican Sign Language is historically and structurally unrelated to either the sign language of the national deaf community, in this case Mexican Sign Language (Lengua de Señas Mexicana, LSM), or the spoken languages of the wider hearing community, Yucatec Mayan and Spanish. ${ }^{7}$

Hearing people in the village speak both Mayan and Spanish, while deaf people are monolingual sign language users. A special education school is available in a nearby larger town, and deaf children from Chican can attend this school, though this does not happen very regularly, and the school staff do not make much use of signs, preferring to focus on speech training and lipreading, which is a common approach in Mexico. Initial fieldwork observations suggest that the local population currently has a rather strong identity as a sign

6. See Section 2.5 for details on the convention of sign language glosses using capital letters.

7. It is, however, related to the conventional gestures used by hearing people in the region (Le Guen 2012). 
language-using village that is distinct from the urban Mexican Sign Language community. A collaborative project between researchers and the local community is currently underway for creating a dictionary of Chican signs (Dikyuva et al. 2012).

Research and documentation of the Chican community goes back to the 1970s, with most research conducted by visitors from the U.S. The American anthropologist Hubert Smith conducted extensive research in Chican over many years and produced a documentary film, archived in the Smithsonian Institution. Other previous researchers have called the sign language "Yucatec Mayan Sign Language" (Du Bois 1978, Shuman 1980, Shuman \& CherryShuman 1981, Johnson 1991, Tree 2009). With the exception of Johnson (1991), previous work has not focused on the sign language itself from the point of view of sign language linguistics. In particular, the linguistic structures have never been documented in any detail.

Although signed communication is being used as the primary mode of communication among deaf and between deaf and hearing Mayans across the Yucatán Peninsula of Mexico, it is not certain at the present stage of research how similar the various varieties of sign language are to each other. The hearing Yucatec Mayans refer to indigenous signing as Ut'aan Kóok Máak "language of deaf persons" (Tree 2009: 361). For the purpose of this article, we refer to Chican Sign Language, abbreviated LSChicana on the basis of the Spanish expression Lengua de Señas Chicana, and our data are limited to the variety of signing used in the village of Chican only.

\subsection{Alipur Sign Language (India)}

The village of Alipur is located in the state of Karnataka in southern India. The village is a small Muslim (Shia) enclave in a predominantly Hindu area, where the main spoken language is Kannada, a language from the Dravidian language family. By contrast, the main spoken language in Alipur is Urdu, and villagers have varying degrees of familiarity with Kannada. There are a few Hindu families living on the outskirts of the village.

Endogamous marriage patterns, maintained over the generations for religious reasons, have resulted in a high incidence of deafness and the emergence of a village-based sign language. The village currently has 150 deaf people out of a total population of about 20,000. Deafness is known to have existed for several generations, and the sociolinguistic situation is similar to what we find for Chican; that is, the majority of hearing villagers are able to communicate in Alipur Sign Language (APSL), though with varying degrees of fluency. The deaf sign language users are monolingual, with no or minimal literacy, and until very recently, no access to formal education. The local population believes APSL dates back over ten generations, but this has not been verified by sys- 
tematic research yet. APSL has only recently been discovered, and research is only just beginning (see Panda 2010, 2011; Dikyuva et al. 2012).

In Alipur, observations from initial fieldwork suggest that deafness carries more of a stigma than is the case, for instance, in Chican. This can be seen in the local arrangements for dowry payments, which put both deaf men and deaf women at a disadvantage, and in the assumption that deaf people cannot be educated, which means deaf boys start working at a very young age. However, these attitudes are now changing, as a deaf school project was started in 2008, and children are now acquiring literacy in English, using the rural sign language as the medium of instruction. Alipur also has its own television channel, which recently began broadcasting some Alipur signs as a community initiative (Dikyuva et al. 2012). Access to other television channels is restricted in the village.

The incidence of deafness is distributed throughout the village, though more strongly represented in particular families, some of which have several continuous generations of deaf people. There is very strong gender separation in the village, and deaf women have fewer opportunities to meet each other outside the immediate family. For deaf men, there are several focal points in the village where they meet regularly, such as a tea stall run by a deaf man, where people can meet and sign, particularly in the evenings.

Recently, there has been increasing language contact with urban sign language varieties, particularly those used in nearby Bangalore, which is an indicator of potential future language endangerment. The numeral signs in APSL may have already been affected by language contact to some extent (cf. Section 3.3).

\subsection{Mardin Sign Language (Turkey)}

Mardin Sign Language (MarSL) exists in an environment that is very different from Chican and Alipur, and it is important to emphasise the variety of situations in which these sign languages are found. The sign language arose in the town of Mardin in south-eastern Turkey. MarSL developed in response to genetic deafness in a single extended family. Interestingly, the family's last name is Dilsiz, which means 'deaf' in Turkish (literally, 'tongue-less').

Use of the sign language in this micro-community goes back to the 1930s, with at least four successive generations (Dikyuva \& Dilsiz 2010). At the time and until recently, no schools or associations for the deaf existed in Mardin, and so far there is little evidence of contact with the urban TID in earlier times. The spoken language environment in which MarSL arose was multilingual, as Turkish, Kurdish, and Arabic are spoken in Mardin. The Dilsiz family's main home language was Arabic, and some evidence of Arabic can be seen in mouth movements that accompany some of the MarSL signs and which derive from 
spoken Arabic. As in the case of Chican and Alipur, MarSL has always been used by both deaf and hearing community members.

About 25 years ago, deaf people began moving out of Mardin to Istanbul and Izmir to find work, and the deaf family members started learning TID, the language of the urban deaf community and its deaf schools and clubs. This has introduced a bilingual situation into the community, with increasing importance of TiD relative to MarSL for the deaf family members. The younger deaf members of the Dilsiz family now predominantly use TiD. Interestingly, MarSL is now maintained chiefly for communication with the hearing family members, who do not use TID. Hearing family members are essentially "sign monolingual"; that is, they only know MarSL. The younger hearing family members have been shifting from Arabic to Turkish over the past decades, but have essentially not learned TID. ${ }^{8}$ Although MarSL is still being used inside the family home and at family gatherings such as weddings, the language is clearly on the brink of extinction. It is estimated to be used presently by 40 individuals of the Dilsiz family, and the fluent deaf and hearing language consultants we have worked with are all in their 50s and 60s. MarSL is only just beginning to be documented (see Dikyuva \& Dilsiz 2010, 2011; Dikyuva et al. 2012). ${ }^{9}$

\subsection{Data summary}

Data that have been used as the basis for this article include both spontaneous conversations and elicited data targeting numerals (see data summary in Table 1).

The Alipur Sign Language data were collected through elicitation games as well as over 30 hours of spontaneous conversations. The elicitation activities consisted of a bargaining game where players "haggled" over the price of an item; an arithmetic game where players performed addition and subtraction using prompt cards with written numbers; and a monetary value activity which involved showing currency notes to signers as prompts to respond with the numerical values.

Mardin Sign Language data include a growing data corpus of currently 20 hours of video recordings with mostly casual conversations, as well as some elicitation. At a language workshop with three elderly consultants in Ankara, we recorded conversations in response to a semi-structured interview, which included some questions designed to elicit numerals, such as asking about the

8. Though this pattern of language maintenance and language shift seems very unusual, it is exactly parallel to the situation in another rural sign language community, Algerian Jewish Sign Language, where the community has moved from Algeria to Israel (Lanesman 2012).

9. The Endangered Languages Documentation Programme is funding a Major Documentation Project on Mardin Sign Language (project reference MDP0200). 
Table 1. Data summary

\begin{tabular}{llll}
\hline & Alipur Sign Language & Mardin Sign Language & $\begin{array}{l}\text { Chican Sign } \\
\text { Language }\end{array}$ \\
\hline $\begin{array}{l}\text { Spontaneous } \\
\text { data }\end{array}$ & 30+ hours & 20+ hours & 20+ hours \\
$\begin{array}{l}\text { Elicited } \\
\text { data }\end{array}$ & $\begin{array}{l}\text { Arithmetic game } \\
\text { Bargaining game }\end{array}$ & $\begin{array}{l}\text { Semi-structured interview } \\
\text { Number listing activity }\end{array}$ & $\begin{array}{l}\text { Arithmetic game } \\
\text { Bargaining game }\end{array}$ \\
\hline
\end{tabular}

price of goods in the "olden days" and about the ages of family members. We also elicited cardinal numerals by doing a listing activity from the consultants. This activity involved writing down series of numbers (e.g., 10, 20, 30, . 100) on a flip chart, to which the consultants pointed and then signed the MarSL numerals. The consultants were asked specifically to give us different variants, so these recordings do show different ways of signing numerals, but all variants are different from TiD.

Finally, the LSChicana data comprises more than 20 hours of spontaneous conversations, and signers playing two of the elicitation games also played by the Alipur Sign Language users: the arithmetic game and the bargaining game.

Some of the elicitation techniques did not work well in all cases, but taken together, the data have provided a clear picture of cardinal numerals in the three sign languages, even if a few types of data had to be excluded from analysis (see Section 3.3 on difficulties with Alipur signers). Further comments on methodological issues are mentioned in Section 5, particularly in relation to the comparability of sign language data and spoken language data.

\subsection{Transcription of sign language data}

As the transcribed sign language utterances presented here might appear unfamiliar to some readers, and glossing practices are not yet fully standardised across the field of sign language linguistics, a short explanation of the conventions used within this article may be helpful. We have employed the generallyaccepted practice of representing individual signs as word glosses in capital letters, and the labelled line on top of these capital letter glosses marks nonmanual features, such as a headshake, a head nod, raised eyebrows, or pursed lips.

In the case of individual signs that require more than one word for the gloss, a hyphen is used between the words, e.g., TWO-AND-A-HALF, which is a single sign. The accent mark ( $\left.{ }^{(}\right)$is used between signs to indicate sequential compounding, e.g., FIVE`TWO for ' 7 ' in MarSL. Repetition of a sign or a 
non-manual component is conveyed by the addition symbol $(+)$, such as in $P A Y++$ 'pay again and again'. The hash symbol (\#) denotes simultaneous morphology, e.g., THREE\#HUNDRED in APSL, or in simultaneous articulation of both hands as in FIVE\#TWO for ' 7 ' (one hand articulates '5' while the other hand articulates ' 2 ').

A complete list of symbols and abbreviations used in this article is provided in the appendix. However, as such transcriptions of signed language do not convey the visual form, we have also included pictorial representations wherever possible. In these representations, the movement in signs is shown by arrows, which are usually self-explanatory, or the picture is accompanied by an explanatory note.

\section{Cardinal numerals in rural sign languages: Findings from the data}

\subsection{Chican Sign Language (LSChicana)}

3.1.1. Numerals below 20. LSChicana expresses numerals 1 through 10 by holding up the corresponding number of fingers, starting with the index finger. There is some variation in the choice and sequencing of this pattern. Urban sign languages using this strategy normally use one hand up to five and then add fingers from the second hand (e.g., five fingers plus two fingers for ' 7 '). However, other variants are found in LSChicana. A variant of EIGHT can be signed using 'four fingers plus four fingers', and there is a sign WEEK derived from this configuration (see Figure 4).

Interestingly, it is possible in LSChicana to have a sequential combination. For instance, holding up five fingers and then one finger can be used for ' 6 '. In those urban sign languages that use the same strategy of holding up fingers, a sequential combination as found in LSChicana is impossible. For instance, in IPSL this sequential combination of FIVE and TWO means '52', but cannot mean ' 7 '. Numerals 11 through 19 involve a sequence of two numeral signs, e.g., TEN ONE for '11', TEN EIGHT for '18', etc. In example (2), taken from

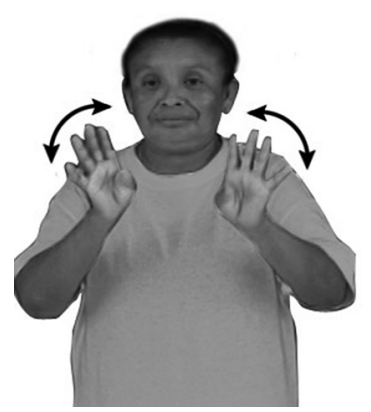

Figure 4. The sign WEEK in LSChicana 


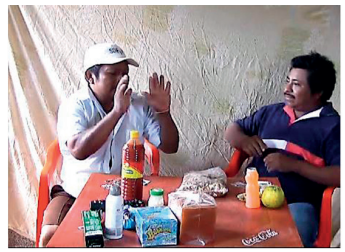

TEN

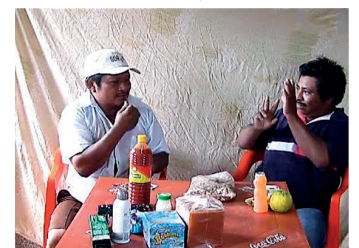

FIVE\#TWO

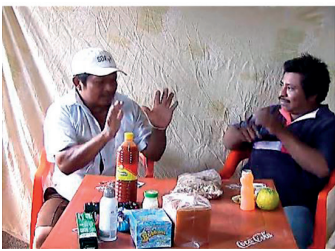

TEN

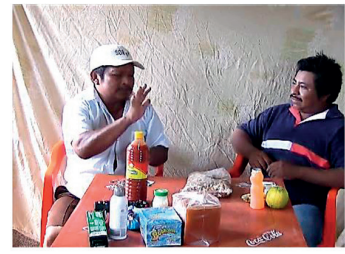

FIVE

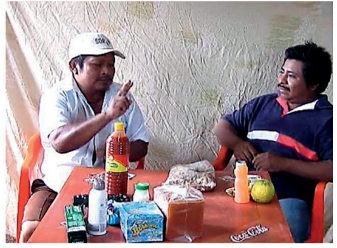

TWO

Figure 5. LSChicana example from the bargaining game

the bargaining game data, Signer A clarifies the price of 17 pesos twice, first using sequential numerals (FIVE followed by TWO), and then the simultaneous two-handed version FIVE\#TWO (see illustrations in Figure 5). The interpretation of the first version as ' 17 ' is confirmed by the voice of a bystander in the background, and Signer B signals comprehension with a repeated head nod at the end of the interchange.

(2) Signer A: TEN FIVE TWO

'It is 17 (pesos)'

Voice in background: Diecisiete

'Seventeen'

Signer B: FIVE\#TWO

'Seven ...'

Signer A: TEN FIVE\#TWO

'Seventeen'

Signer B: nod++ 
3.1.2. Additive bases 20 and 50. In order to produce higher numerals, LSChicana uses an additive strategy. Numerals are built by successive addition from the additive base numerals 50,20, and 10, in sequence from largest to smallest numeral. This is comparable to cases of spoken languages with several numeral bases (cf. type "tribasico" - having three bases - in Barriga Puente 1998). However, in typical vigesimal systems found in spoken languages, the base 20 is used as a multiplicative base, as is the case in Mardin Sign Language (see Section 3.2.2). The LSChicana system has separate lexemes for 20 and 50 that are used for adding up, but it is not vigesimal in the usual sense, as 20 is not used as a base in any other arithmetic operations beyond sequential addition.

Example (3) from the conversational data corpus illustrates these numeral expressions, where a signer discusses how the costs involved in producing a hammock have been rising over time due to inflation. TEN is produced by presenting ten extended fingers, and the sign TWENTY is formed by two flat hands on the knees, probably derived iconically from counting ' 10 fingers and 10 toes'. '30' is indicated by the juxtaposition of TWENTY and TEN, and finally, ' 60 ' is indicated by the juxtaposition of FIFTY and TEN.

\section{STITCH OK PAY MONEY CUT FRAME STITCH NAIL nod++ TWENTY THEN TWENTY TEN THEN FIFTY TEN}

'To stitch (a hammock) you need to buy a frame to stitch and nail it onto; (the cost has been) 20, then 30 and then 60 (pesos).'

From the iconicity of the sign, it is clear that FIFTY is related to the concept of 'half'. We do not know of any documented case of an urban sign language with a separate, monomorphemic lexeme for ' 50 ', though there are similar signs in MarSL and APSL (see Sections 3.2 and 3.3). Figure 6 shows the signs for ' 30 ' and ' 50 ' in LSChicana.

While a base numeral ' 50 ' is rare in spoken languages, base-20 (vigesimal) systems are a well-established type in spoken languages, e.g., in Comrie (2005a). Base-20 numeral systems occur in particular in a number of indigenous spoken languages in Mexico, including the variety of Yucatec Mayan used in Chican. However, the LSChicana numerals are not necessarily the result of language contact, as base-20 numerals can arise without any evidence of such numeral systems in surrounding spoken languages, as the case of Mardin Sign Language proves (see Section 3.2). Also note that in LSChicana, 20 is used as an additive base and not as a multiplicative base.

The following example of the additive strategy in LSChicana is taken from the arithmetic game activity. Two signers are involved in this game, using numbers with arithmetic operations written on cards as prompts. TWENTY TWENTY FIVE ' 45 ' was produced in response to a stimulus card. As mentioned in Section 1.2, in urban sign languages addition is used in the formation 


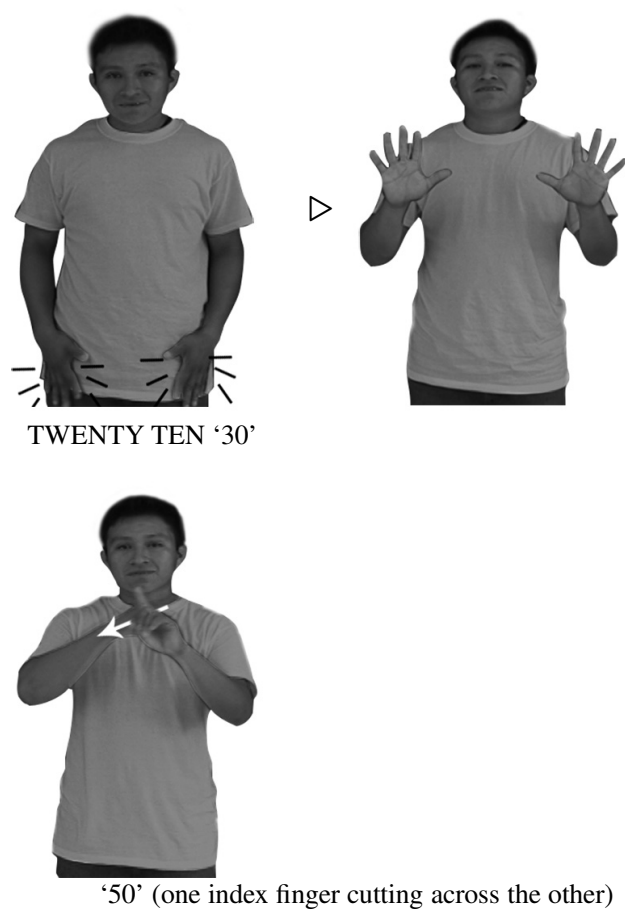

Figure 6. Multiples of 10 in LSChicana

of cardinal numerals, but the building blocks are multiples of thousands, hundreds, tens, etc. There are no documented instances in urban sign languages of numerals built up from additive sequences of the "multiples of 10" series, such as ' $50+20+10$ ' for ' 80 ' in LSChicana.

3.1.3. Numerals above 100. For higher numerals, LSChicana uses lexical signs, and the structures are in line with what we find in urban sign languages (cf. Section 1.2). There are lexical signs for HUNDRED (see Figure 7) and THOUSAND. Both patterns are instances of multiplication where the multiplication operation itself is unexpressed, e.g., '2,000' is TWO $(\times)$ THOUSAND. These structures are familiar from urban sign languages.

\subsection{Mardin Sign Language}

3.2.1. Numerals below 20. The MarSL numerals below 20 are similar to what we have seen in LSChicana. Figure 8 shows the numeral signs from 1 to 10 as produced by the main consultant, an elderly deaf man. 


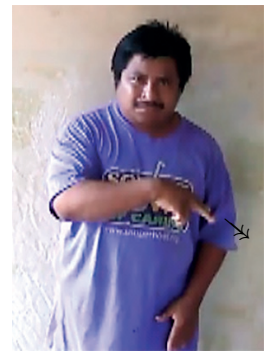

Figure 7. HUNDRED in LSChicana (two extended fingers, repeated movement)
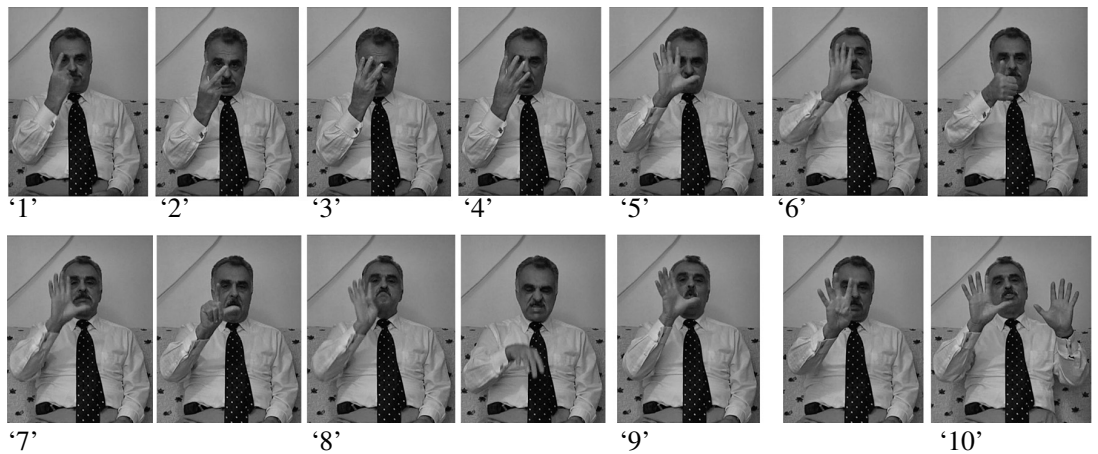

Figure 8. Mardin Sign Language number signs 1 to 10

Similar to LSChicana, several numerals have a sequential combination with '5', i.e., FIVE`ONE for '6', FIVE'TWO for '7', and FIVE^FOUR for '9'. In these cases, there is a greater degree of formational fusion between the two signs, including a twist of the wrist for ' 6 '. Therefore, these signs are analysed as sequential compounds. The formation of ' 8 ' is also interesting, clearly being derived from '4+4', but with a wrist bending movement pattern. From 11 to 19, $T E N$ is combined with the smaller numeral in sequence, as in LSChicana, e.g., TEN FIVE for ' 15', or the subtractive strategy may be used (see Section 3.2.3).

3.2.2. Numerals 20 through 100. The numerals for multiples of 10 are particularly complex in Mardin Sign Language. The sign TWENTY (see Figure 9) is one-handed and has a handshape with bent thumb and index finger. TWENTY is accompanied by a characteristic lip smack. The sign THIRTY starts with the extended thumb and index finger, followed by a wrist twist while the thumb approaches the index finger (Figure 9). The latter part of the sign is very simi- 


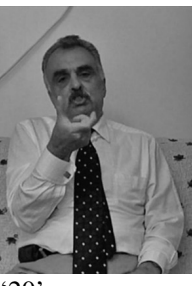

' 20 '

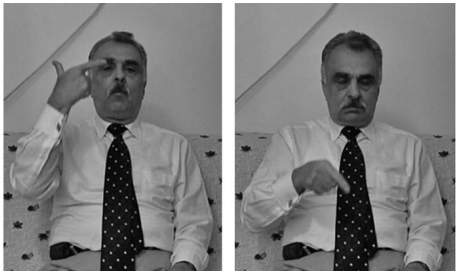

30' (downward twisting wrist, fingers closing)

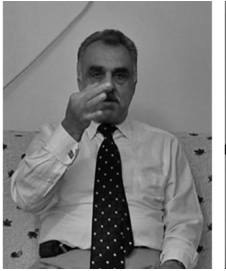

'50' (thumb cutting ' 75 ' across index)

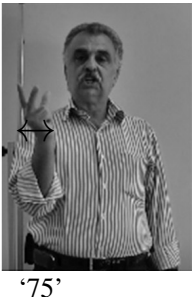

Ein

Figure 9. The signs TWENTY, THIRTY, FIFTY, and SEVENTY-FIVE in Mardin Sign Language

lar to what we find in the signs for ' 70 ' and ' 90 ', while the initial configuration resembles the numeral TWENTY, but without bending of the fingers. This is clearly a very fused form, but an underlying mathematical operation is not evident, and so the sign is provisionally classified as monomorphemic here.

Similarly to LSChicana, Mardin Sign Language also uses (a reduced form of) ' 50 ' as a building block in numerals. The sign for ' 50 ', with the thumb "cutting" across the index finger, is iconically motivated and identical to the sign $H A L F$ (i.e., 'half of 100'). Finally, and uniquely among the sign languages discussed here, there is a monomorphemic lexical sign for SEVENTY-FIVE (see Figure 9). The monomorphemic sign SEVENTY-FIVE was produced consistently by all three signers participating in the number listing activity, and no alternative compositional form is found in our data.

For the numerals 40,60,70,80, and 90, we find two distinct sub-systems. The series $40,60,80$ follows a vigesimal system based on ' 20 ', but where the base ' 20 ' remains unexpressed. The numeral signs are produced by flicking out two, three, and four fingers respectively from a closed hand. The hand usually moves upwards at the same time. For instance, when the thumb, index, and middle fingers are flicked out, this means ' 60 ', i.e., $3 \times 20$. This particular movement is not found anywhere else in MarSL numeral signs. The movement is clearly indicative of multiplication with 20 , but does not contain the sign $T W E N T Y$ in any clearly recognizable way. Figure 10 shows the signs from this series.

The numerals for ' 70 ' and ' 90 ' constitute a second sub-system, which involves addition and is based on combinations with the concept of 'half' (see Figure 11).The signs have three formational elements: extended fingers followed by wrist twist and a "cutting across" movement for 'half', where 'half' implicitly refers to 'half of 100 ', i.e., ' 50 '. The sign for ' 50 ' $(H A L F)$ is identical to the last part of '70' and ' 90 ', except that the "cutting" movement in $H A L F$ is usually repeated. In ' 70 ' and ' 90 ', there is no repetition, so the form 

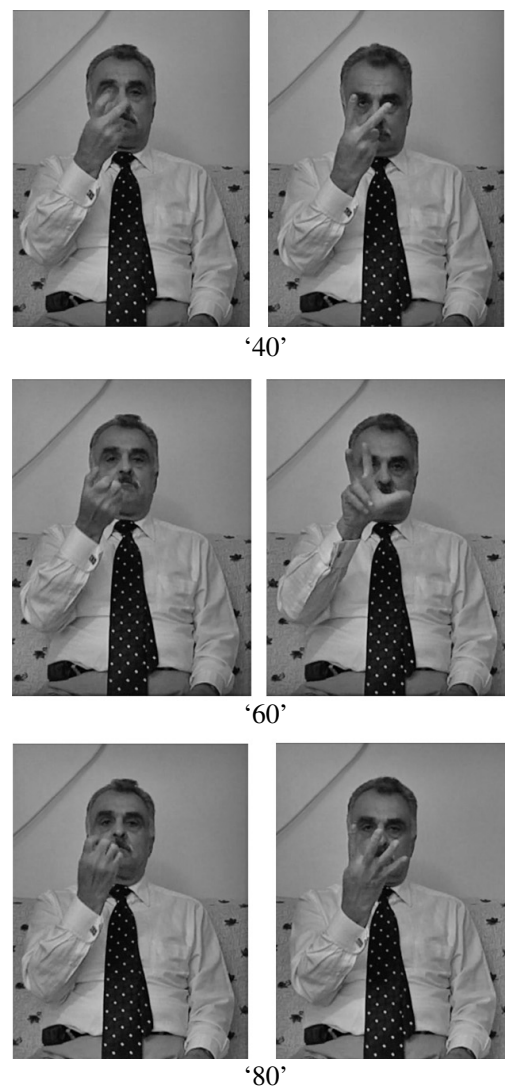

Figure 10. The signs for '40', '60', and '80' in Mardin Sign Language

is reduced and more fused with the other elements. For ' 70 ', the sign starts with two extended fingers, and '90' starts with four extended fingers (excluding the thumb). The underlying arithmetic operation therefore seems to be $20+50$ for '70' and 40+50 for ' 90 ' respectively, though these formations show a considerable degree of fusion, and in the first part, ' 2 ' actually stands for ' 20 ' and ' 4 ' stands for ' 40 '. ${ }^{10}$ This is the only instance in all our data where the larger numeral follows the smaller numeral.

10. This also happens in Alipur Sign Language (see Section 3.3.4). 

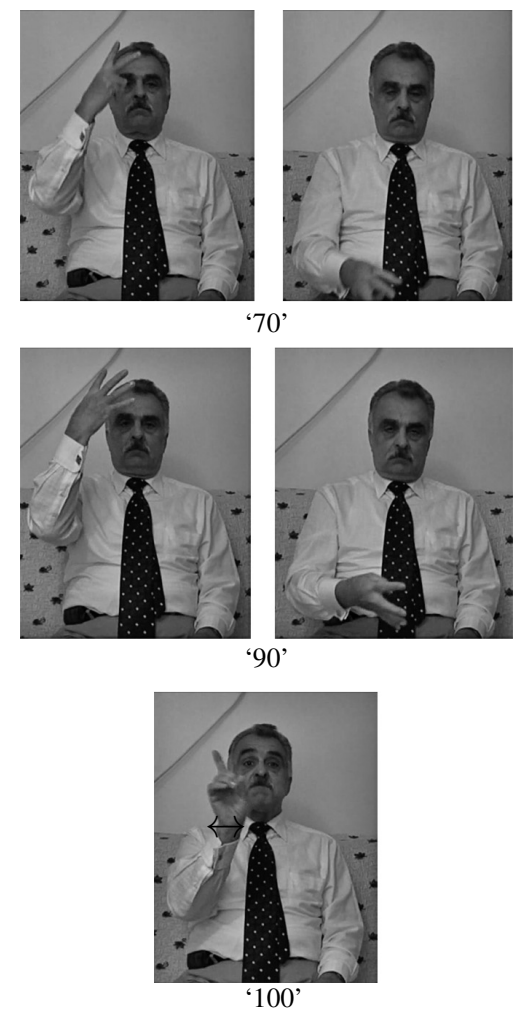

Figure 11. The signs for '70', '90', and '100' in MarSL

The sign for ' 100 ' in MarSL is again monomorphemic, using a to-and-fro motion with an extended finger (see Figure 11). Multiples of '100' use simultaneous morphology as in LSChicana (two extended fingers for '200', etc.). HUNDRED has an accompanying mouth pattern mi, often repeated as mimi or mimimi. This is clearly influenced by the surrounding spoken language, as ' 100 ' is mi' $a$ in spoken Arabic.

In summary, the multiples of 10 are based on the arithmetic operations shown in Table 2 (the terms in brackets are not overtly expressed).

It is interesting to see the various degrees of fusion in the MarSL numerals, as this is indicative of a historical process taking place in the history of the language. These numerals constitute independent linguistic evidence that Mardin Sign Language has indeed existed for a number of generations, as is suggested by the sociocultural information that we have gathered about this language (cf. Section 2.3). Such fused forms are also found in the numeral sys- 
Table 2. Multiples of 10 in Mardin Sign Language

\begin{tabular}{cll}
\hline Number & Compositionality of the sign & Arithmetic operation \\
\hline 10 & & monomorphemic \\
20 & monomorphemic \\
30 & $(20) \times 2$ & monomorphemic \\
40 & & multiplication, base 20 \\
50 & $(20) \times 3$ & monomorphemic \\
60 & $2(0)+$ half (of 100) & multiplication, base 20 \\
70 & $(20) \times 4$ & addition \\
80 & $4(0)+$ half $($ of 100$)$ & multiplication, base 20 \\
90 & & addition \\
100 & & monomorphemic \\
\hline
\end{tabular}

tems of other sign languages, for instance in Mexican Sign Language (Cesar Ernesto Escobedo Delgado, personal communication), but the MarSL numerals are particularly complex with respect to the underlying arithmetic operations.

Finally, it should be noted that the complex numeral system is a languageinternal development in MarSL. That is, neither base-20 numerals nor combinations with '50' are attested in any of the spoken or signed languages that MarSL could have been in contact with (Turkish Sign Language, Kurdish, Turkish, Arabic). This is despite the fact that there is evidence of the influence from spoken Arabic in characteristic mouth movements that occur together with some of the numeral signs in the data. It is remarkable that such a small community of signers has innovated such complex numeral structures that are crosslinguistically quite rare.

3.2.3. Subtractive strategy. Mardin Sign Language also has a subtractive sub-system, which is not obligatory but constitutes one possible option. In Mardin Sign Language, only the values one to four appear as subtracted numerals. TWENTY TWO-LESS '18' and TWENTY ONE-LESS '19' were produced by signers involved in the number naming task (see Figure 12). This construction is possible from 26 to 29 , from 36 to 39 , etc., although it seems some signers use it only for $28 / 29,38 / 39$, and so forth. In elicitation, the male deaf consultant accepted subtractions up to four, while one of the hearing female consultants only accepted ONE-LESS and TWO-LESS.

Other values cannot be expressed using subtraction. Instead, '24' would be signed using an additive strategy as TWENTY FOUR. ${ }^{11}$ Thus the subtractive

11. This is also an additional option for the numbers with digits 6 to 9 , so use of the subtractive system is not compulsory. 


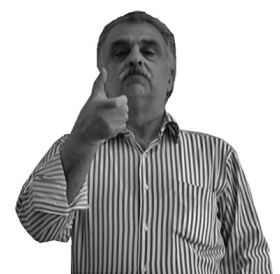

TWENTY

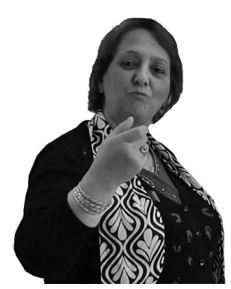

TWENTY

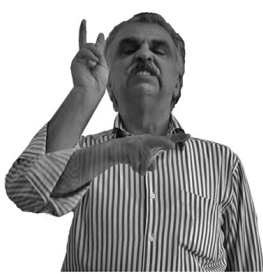

TWO-LESS

' 18 '

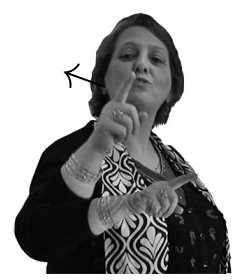

ONE-LESS

' 19 '

Figure 12. Subtractive numerals in MarSL

numerals in Mardin Sign Language have only been observed as a small subsystem, and their infrequent use means that they do not occur in the conversational data. Therefore, further data are needed in order to detect the exact scope and usage of subtractive numerals in this sign language.

\subsection{Alipur Sign Language}

3.3.1. Introduction. Alipur Sign Language (APSL) shows the greatest internal variation among our data, with several strategies to express numerals, depending on the context and the participants. This includes additive, subtractive, and digital numerals as well as morphological processes. A given numerical value can often be expressed in APSL using more than one strategy.

During the elicitation games, many of the deaf consultants appeared to have some difficulty with the tasks in terms of responding to overt questions about numerals. Not everyone was used to mental arithmetic, which is required for the arithmetic game activity, but it was possible to obtain data from some signers. Although the responses to the arithmetic task were often factually wrong (e.g., sometimes signers confused the $\times$ indicating multiplication with the + indicating addition), the aim of the game was to prompt signers to produce numerals, and this aim was accomplished. Whether the mathematical calculation itself was right or wrong is irrelevant to the data. The bargaining game was more successful, as bargaining is an everyday activity in the village. Data from another elicitation task based on asking people to sign written numbers (the 
same kind of activity that was conducted with the three participants of Mardin Sign Language) were discarded because the signers seemed unduly influenced by the writing and produced numerals following the written digits, which is not characteristic of usage in other contexts. It was important to cross-check data obtained through elicitation activities with data from casual conversations, and the data presented here are representative of both elicitation and conversations.

3.3.2. Additive strategy. As in Chican Sign Language, APSL uses additive strategies to express cardinal numerals. Numerals from one to nine are shown iconically using the corresponding number of extended fingers. However, there is an alternative way of articulating the numeral ' 5 ', glossed $F I V E(b)$, involving an internal movement that closes the palm. Numerals above ' 5 ' involve simultaneous addition, including the numeral ' 10 ', which uses two closing hands, that is, $F I V E(b) \# F I V E(b)$. FIVE $(b)$ is restricted to contexts of ' 5 ' and ' 10 ' and their multiples, but is not used to form numerals between ' 6 ' and ' 9 '. Multiples of 10 use repetition of $F I V E(b) \# F I V E(b)$, up to ' 40 ', while ' 50 ' is a separate lexeme (see Figure 13).

As in LSChicana, there is a degree of variation between and within signers in the form of these numerals. However, the APSL variation is governed by the above constraints, e.g., on the use of $F I V E(a)$ vs. $F I V E(b)$. It may well be that the iconic nature of these signs, which make them easy to interpret, together with the absence of formal education, contributes to greater variability in the form of numerals below 10 . There is much less variability in the expression of higher numerals in our data.

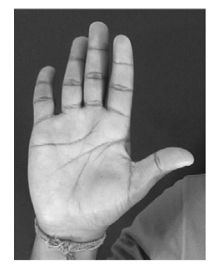

FIVE (a)

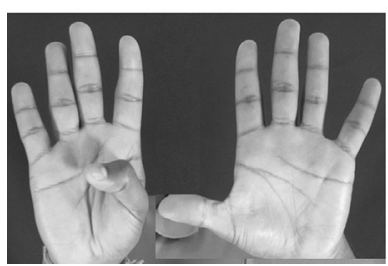

NINE

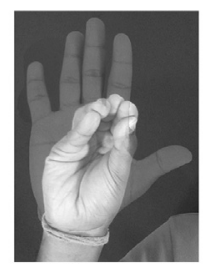

FIVE (b)

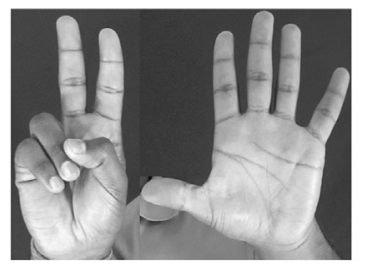

SEVEN

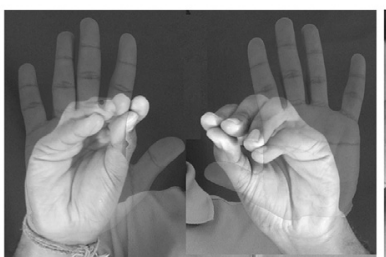

TEN

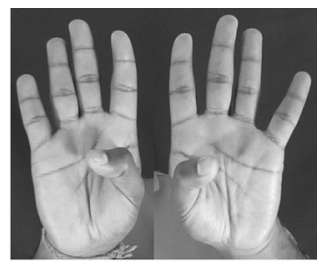

EIGHT

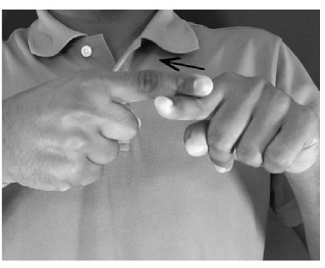

$\operatorname{HALF}$ ('50’)

Figure 13. Numerals in Alipur Sign Language 
The numeral ' 50 ' acts as an additive base for numerals larger than 50 , and this is expressed as the sign $H A L F$ followed by the requisite further numerals in sequence from largest to smallest, e.g., HALF TEN TWO '62'.

3.3.3. Simultaneous morphological processes. In APSL, numerals can be derived using simultaneous morphology, and one type of morphological derivation involves spatial modification of the sign, a process that has not been documented for any other sign language so far.

Spatial modification is based on the sign HUNDRED and is used for numerals from ' 1,000 ' onwards. The size of the sign is enlarged spatially, resulting in three different "augmentative" forms: slightly enlarged for ' 1,000 ' (glossed HUNDRED ${ }^{\text {augl }}$ ), considerably enlarged for '100,000' (glossed HUN$D R E D^{\text {aug2 }}$ ), and maximally enlarged for non-specific reference to very large numbers beyond 100,000 (glossed $H U N D R E D^{\text {aug3 }}$ ). The system partly parallels the Hindi/Urdu numerals, where there is a lexeme for ' 100,000 ' (lakh in Hindi/Urdu; cf. Section 1.2 for IPSL, which also has a sign $L A K H)$. However, APSL does not have a sign for ' $10,000,000$ ' (crore in Hindi/Urdu).

The augmentative forms of HUNDRED are usually accompanied by mouth movements derived from Hindi/Urdu numeral and quantifier words, respectively hazar '1,000', lakh '100,000', and bahut ('a lot'). The Hindi/Urdu mouthings add clarification between different values. In addition, non-manual features can optionally be added. A diminutive meaning (e.g., 'only 1,000', when more was expected) is conveyed by squinted eyes, and an intensive meaning (e.g., '1,000!!' when this is considered a huge quantity) is conveyed by raised eyebrows and/or widened eyes. HUNDRED $D^{\text {aug } 2}$ and $H U N D R E D^{\text {aug3 }}$ only occur with intensive non-manuals, but not with diminutive in our data. Intensive and diminutive non-manual expressions are not particular to numerals, but occur with other types of signs too. As seen in Table 3, a numeral can have several simultaneously occurring manual and non-manual components.

In addition to spatial morphology, APSL also employs simultaneous morphology for multiplication through "numeral incorporation" (see Section 1.2 above). This generates multiples of 10 and multiples of 100 in APSL by combining numeral handshapes with movement patterns, both of which are optional (Figure 14, left and middle). Multiples of $10 \mathrm{can}$ also be expressed using combinations of $F I V E(b) \# F I V E(b)$ and $H A L F$, while for multiples of 100 , the signs can also be produced separately: HUNDRED THREE, THREE HUN$D R E D$, and THREE\#HUNDRED may be used for ' 300 '. Unlike in Hindi/Urdu (tiin sou, i.e., three hundred), the order of elements is flexible in the APSL construction. Simultaneous morphology also applies to restrictive numerals in APSL (e.g., 'only two', articulated with wiggling fingers and the hand moving upwards), which belong to a separate numeral series (Figure 14, right). 
Table 3. The APSL sign HUNDRED and its augmentative forms

\begin{tabular}{|c|c|c|c|c|}
\hline & 100 & 1,000 & 100,000 & $\begin{array}{l}\text { vague large } \\
\text { numbers }\end{array}$ \\
\hline $\begin{array}{l}\text { Non- } \\
\text { manual }\end{array}$ & $\begin{array}{l}\text { diminutive/ } \\
\text { intensive } \\
\text { mouthing sou }\end{array}$ & $\begin{array}{l}\text { diminutive/ } \\
\text { intensive } \\
\text { mouthing hazar }\end{array}$ & $\begin{array}{l}\text { intensive } \\
\text { mouthing lakh }\end{array}$ & $\begin{array}{l}\text { intensive } \\
\text { mouthing bahut }\end{array}$ \\
\hline Manual & $\begin{array}{l}\text { HUNDRED } \\
\text { Palms in contact } \\
\text { or very close } \\
\text { together }\end{array}$ & $\begin{array}{l}\text { HUNDRED }{ }^{\text {aug } 1} \\
\text { Small distance } \\
\text { between hands }\end{array}$ & $\begin{array}{l}\text { HUNDRED aug2 } \\
\text { Wide distance } \\
\text { between hands }\end{array}$ & $\begin{array}{l}\text { HUNDRED aug3 } \\
\text { Maximal } \\
\text { distance between } \\
\text { hands }\end{array}$ \\
\hline Sign & & & & \\
\hline
\end{tabular}

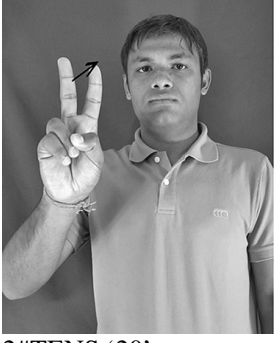

2\#TENS '20’

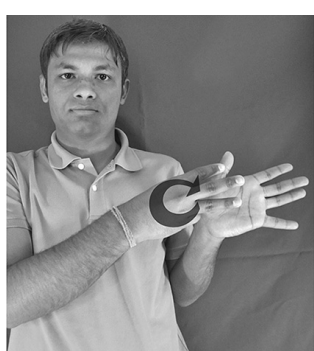

THREE\#HUNDREDS ‘300' 2\#restrictive 'only 2'

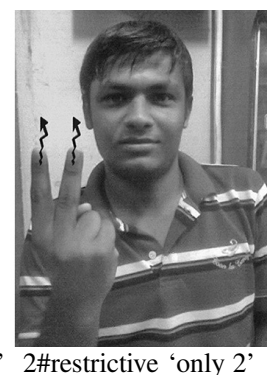

Figure 14. Numeral signs with simultaneous morphology in APSL

3.3.4. Subtractive strategy. APSL does not use ' 20 ' as an additive base, but there is an alternative that allows signers to limit the length of strings of signs needed to express any numeral. This involves a subtractive sub-system. In APSL, subtractive numerals are used when the value in question is near a higher "round" number. For instance, '195' can be expressed as '200 minus 5', using the sign LESS. The following examples are from the data (see also 


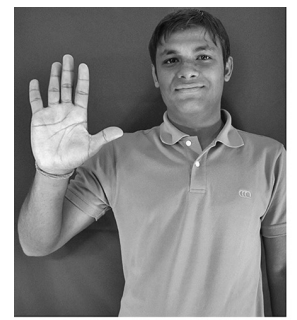

FIVE

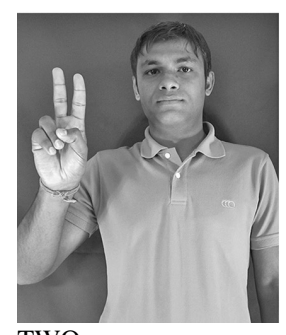

TWO

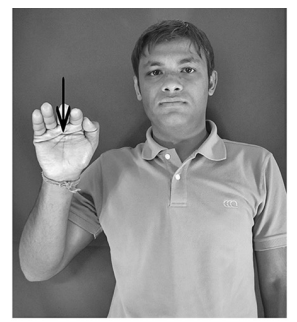

LESS

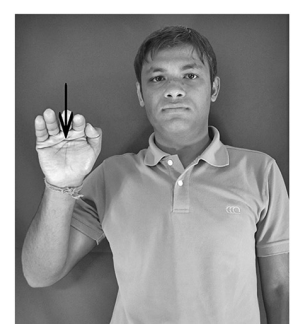

LESS

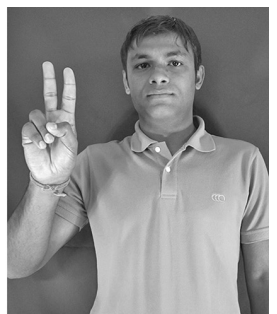

TWO

' 195 '

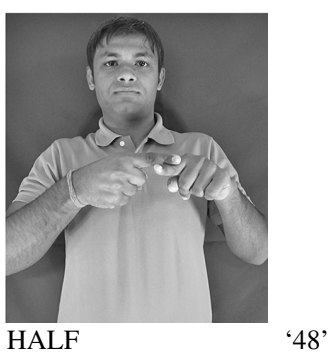

Figure 15. Subtractive numerals in APSL

Figure 15): FIVE(a) LESS TWO' '195', TWO LESS HALF '48', TWO LESS THREE '28'.

With respect to the order of the signs in the subtractive sub-system, the data show that the usual order of signs is to start with the numeral that is being subtracted, followed by the sign LESS, followed by the larger numeral that is being subtracted from. Sometimes, signers topicalise the larger numeral, in which case it appears first but is marked as topic with raised eyebrows and a following pause, as in (4b). This kind of non-manually marked topicalisation is common in sign languages. The choice of sign order seems to depend on the context of the utterance, but this has not been investigated in detail.

$$
\begin{array}{ll}
\text { a. } & \text { TWO LESS HALF } \\
\text { ' } 48 \text { ' } & \frac{}{H A L F} \text { ' } \\
\text { ' } 48 \text { ' }
\end{array}
$$

12. TWO is used to mean '200', and this is a type of ambiguity regularly used in APSL. Similarly, THREE in TWO LESS THREE '28' stands for '30'. Disambiguation depends on the context in these cases. 
Subtractive numerals that can be constructed flexibly in this way are very rare crosslinguistically. A number of spoken languages have subtractive singledigit numerals (e.g., Hurford 1975, Greenberg 1978). For instance, in Athapascan languages, ' 9 ' is regularly expressed as '(10) minus 1' (Hymes 1955). However, the subtractive sub-system is productive in APSL, and that makes it highly unusual.

The subtractive numerals in the above examples are not obligatory in APSL, but constitute a common way of communicating a numerical value in specific situations. That is, for values that are just below a higher "round" number, the subtractive numerals are an easier way that avoids having to count "upwards" in the additive system. For instance, expressing ' 195 ' would require the following set of numerals if the additive strategy was used: HUNDRED HALF TEN TEN TEN TEN FIVE. Instead, the expression FIVE(a) LESS TWO is more economical.

3.3.5. Digital strategy. Sometimes a digital strategy is used in APSL, which is very similar to the Indo-Pakistani Sign Language (IPSL) system described in Section 1.2. For example, '195' may be expressed as ONE NINE FIVE instead of using the subtractive system. This strategy it is not commonly used by older signers, which suggests that it is a recent, possibly contact-induced, development. ${ }^{13}$

In the data corpus for APSL, the digital strategy appears in particular where data elicitation techniques were used with signers (see Section 2 about the data corpus). The following is an example from an elicitation activity where signers were shown various combinations of bank notes and were asked to sign the amount of money as a response to the researcher: FIVE\#TWO FIVE(a) ' 75 '. In spontaneous conversations, the digital strategy is marginal in APSL. The rural sign languages in Mexico and Turkey show no evidence at all of a digital strategy for numerals above ten, even under conditions where written stimuli were used in data elicitation, which was the case for both MarSL and LSChicana.

\section{Summary of findings}

\subsection{Typological variation in sign languages}

The data in this article demonstrate clearly that typological variation in cardinal numerals is much broader in sign languages than has previously been recognised by sign language linguists. Although no systematic survey of numeral systems in sign languages has been undertaken yet, many structures ob-

13. In 2008, a school was set up in Alipur to create educational opportunities for deaf children, and this has resulted in increased language contact with urban sign languages and with writing. 
served in LSChicana, APSL, and MarSL are currently unattested in urban sign languages. A future more comprehensive survey would allow us to ascertain with more certainty whether these structures also exist in some urban sign languages, but until then, the rural sign language data provide the only attested cases of these structures. This is not unexpected, as spoken language typology has similarly been broadened by data from "exotic" spoken languages. Previous work in sign language typology has likewise shown that typological variability across sign languages is broader than previously anticipated in the domains of interrogatives, negatives, and possession (Zeshan 2004a, b; Zeshan (ed.) 2006; Zeshan \& Perniss (ed.) 2008).

The cases of non-decimal numeral bases and subtractive sub-systems are particularly striking because they occur in more than one rural sign language, and though not currently attested in other sign languages, they are well-attested patterns in spoken languages.

4.1.1. Non-decimal numeral bases. Several instances of crosslinguistically unusual numeral bases (i.e., unusual for sign languages) occur in our data. All three rural sign languages use ' 50 ' as an additive base, while LSChicana and MarSL use a numeral base ' 20 ' as an additive and multiplicative base respectively. ${ }^{14}$

An additive strategy of the kind discussed for LSChicana and APSL seems to occur in urban sign languages only for numerals between 10 and 20. A number of urban sign languages build the 'teen' numerals as a sequential combination of the sign for ' 10 ' plus the single-digit numeral, i.e., TEN THREE for 'thirteen', as can be seen, for instance, in some dialects of the sign language varieties used in the Levantine Arab area (see Hendriks \& Zeshan 2009 on Levantine Arab Sign Language). However, an additive system for numerals higher than 20 is uncommon or non-existent in urban sign languages.

It is easy to see why sign languages with a 10-based numeral system would require a multiplicative strategy rather than adding up successive repetitions of ' 10 '. After more than a few repetitions, such a system is difficult to use, as for a numeral such as 80 one would need eight repetitions. The sign languages in Chican, Alipur, and Mardin avoid this problem by having additive numeral bases greater than 10. For instance, in order to express any numeral below 100, no more than four signs in sequence will ever be needed in LSChicana, as exemplified with the numeral 99: FIFTY TWENTY TWENTY NINE. It is striking that all three rural sign languages in our data corpus have an additive numeral base 50, the signs for which are all iconically motivated and represent the con-

14. Note that the use of monomorphemic signs for ' 20 ' and ' 50 ' as additive bases is different from the numeral SEVENTY-FIVE in MarSL, which is also a monomorphemic sign but does not act as a numeral base, as it is not used in the formation of any other numerals. 
cept of "half". APSL and LSChicana use a two-handed sign to indicate 'half' for ' 50 ', while the MarSL sign is one-handed. The cultural, linguistic, and sociolinguistic information available about these sign languages, as described in Section 2, excludes the possibility of direct or indirect borrowing through contact, or through a shared genetic origin. Therefore, the conclusion must be that the cognitive basis of these signs, taking half of 100 , has arisen in these three sign languages independently of each other, using the same underlying iconicity. This is not unusual in sign languages, as has been argued in Zeshan (2010); using the same iconic basis can lead to similar or even identical signs in sign languages that have no history of contact. For example, many sign languages use a range of similar, iconically motivated forms for negative particles (Zeshan (ed.) 2006). However, the case of non-decimal numeral bases is peculiar because these numerals arose in several rural sign languages independently, yet such numerals are not attested in any urban sign languages, either in proximity to these rural sign languages or otherwise; neither Mexican nor Indian (IndoPakistani) nor Turkish Sign Language have non-decimal numeral bases, and only one of the surrounding spoken languages (Yucatec Mayan) has vigesimal numerals. We return to this issue in Section 4.2.

4.1.2. Subtractive sub-systems. Alipur Sign Language and Mardin Sign Language are the first-ever documented sign languages with a subtractive subsystem. Therefore, these data constitute new evidence of extended typological variation in sign languages. Moreover, the subtractive sub-system in APSL is productive, and this is very unusual in both signed and spoken languages. The fact that both subtractive sub-systems are optional does not diminish the importance of these data, but rather calls for a more in-depth, corpus-based analysis of their usage. In the APSL data, initial evidence suggests that use of the subtractive numerals is governed by several discourse and interpersonal factors, such as who the interlocutors are and what other numerals are present in the discourse. For instance, a common pattern in the "bargaining game" is for the participants to begin by using additive numerals, and then switch to subtractive numerals, as the context is established. Moreover, the use of single digits to refer to multiples (e.g., TWO for '200' as in Figure 15) may be dependent on a previous communicative context.

4.1.3. Conclusions for crosslinguistic variation in sign languages. Two conclusions can be drawn from these data for the typological variability of sign languages. Firstly, it is becoming increasingly evident that typological diversity across sign languages is far greater than previously recognised. Even within the sign language linguistics community, this is a relatively new development. So far, all large-scale crosslinguistic studies of sign languages have found a very substantial variety of structures (cf. Zeshan 2004a, b; Zeshan (ed.) 
2006; Zeshan \& Perniss (eds.) 2008), and the field of sign language typology has put the issue of typological diversity across sign languages firmly on the research agenda. The systematic comparative study of "rural sign languages" is the logical continuation and expansion of previous work in sign language typology.

Secondly, the data preclude any simplistic typology in terms of "rural sign languages" as a separate sub-type that could be contrasted with "urban sign languages" as a group..$^{15}$ The three sign languages in our data differ from urban sign languages, but they also differ considerably from each other. A parallel conclusion has been drawn in Zeshan (2010) concerning crosslinguistically unusual features of spatial grammar in several rural sign languages.

Table 4 summarises the differences between the sign languages discussed in this article, for numerals up to 100. Turkish Sign Language, Mexican Sign Language, and Indo-Pakistani Sign Language are used as representatives of urban sign languages. The table clearly illustrates that each sign language has its own unique system. For instance, IPSL has the simplest system, using only the digital option. MarSL and APSL both have complex numeral systems with a range of structures, but choose different options from the available set of possible structures. The shaded areas in the table show the features of numerals that are not found in other sign languages so far (numeral bases greater than 10; subtractive numerals; spatial modification).

\subsection{Typological variation in signed and spoken languages}

The data discussed here indicate that when we consider an increased range of typologically diverse sign languages, we find a complex pattern that is schematically represented in Figure 16. Data from spoken languages are represented by circles while sign languages are represented by squares in the figure.

It is clear even from the present small case study that there are both modalityspecific structures and structures where patterns cut across language modality. On either side of the diagram, there is a space where structures are specific to signed and spoken languages respectively. However, the larger part of the typological space consists of features of numerals that are found cross-modally, and where some sign languages pattern with particular spoken languages rather than with other sign languages. For example, vigesimal systems include a number of spoken languages, but also a part of the MarSL paradigm. Subtractive

15. Contrasting "rural sign languages" and "urban sign languages" is far too simplistic anyway, and even the terms may not really be adequate. However, terminology has not been established in this field of research yet, and other terms are used in the literature, such as "shared signing communities" in Kisch (2008). Meir et al. (2010) use the terms "village sign languages" and "deaf community sign languages". A discussion of various terms can be found in de Vos \& Zeshan (2012). 


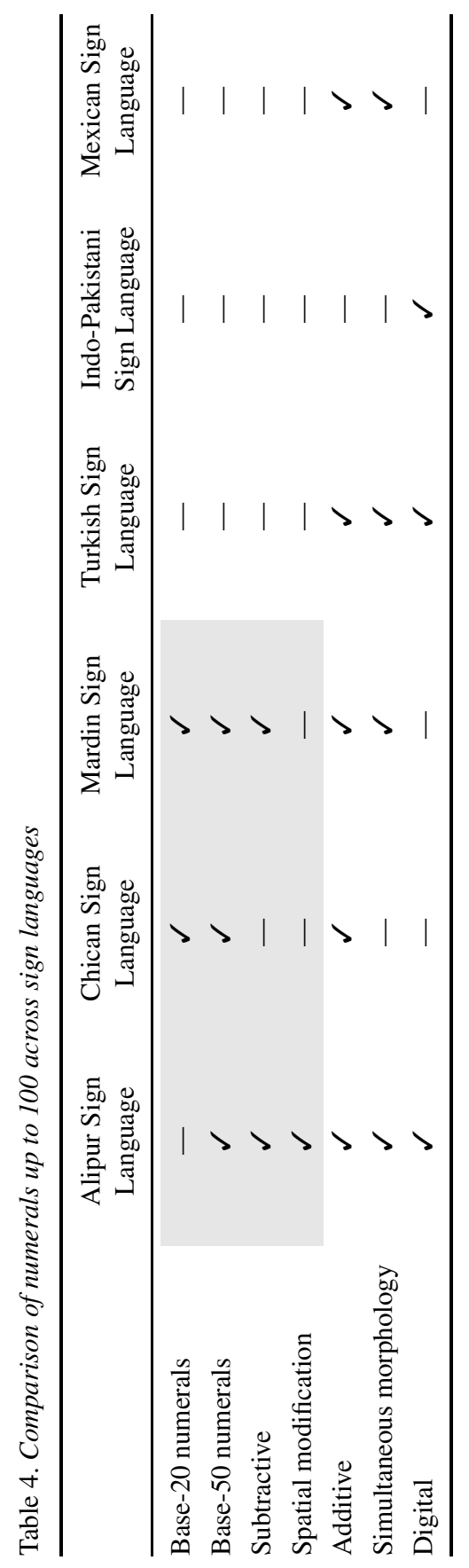




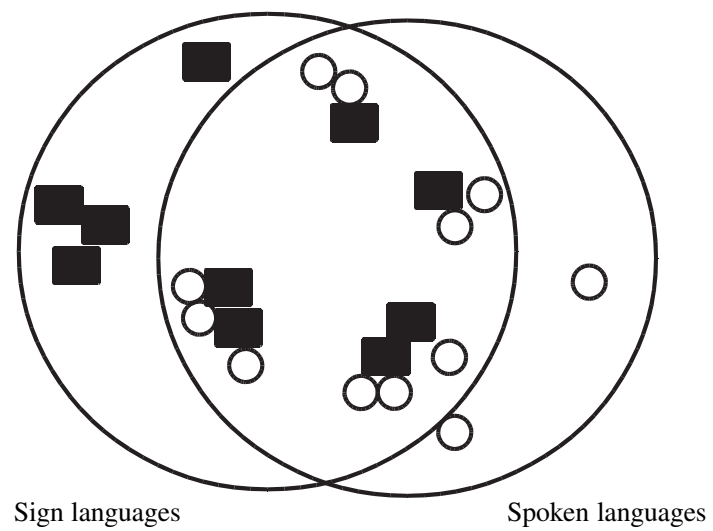

Figure 16. Cross-modal typological patterns of variation in signed and spoken languages

numerals are found in certain spoken languages as well as in MarSL and APSL, but not in other sign languages documented so far. In such cases, the organisation of the typological space therefore cuts across modalities, and it is the abstract system (e.g., basing numerals on '20') that is important rather than the language modality in which this system is instantiated.

As far as language modality effects are concerned, we do see some structures that are only found in certain sign languages but not in spoken languages, and vice versa. Morphological structures not found in spoken languages include the simultaneous morphology of "numeral incorporation" and spatial modification. The former occurs in sign languages due to a general tendency of preference for simultaneously realised morphology. Structures such as in Figure 3 are typical of numerals in many sign languages, whereas the equivalents in spoken languages have sequential morphology. The second instance, spatial modification, is only available in sign languages due to the language modality. This also applies to non-manual features that are part of cardinal numerals, such as mouthings in APSL and MarSL, or intensive and diminutive forms in APSL.

Another type of system that is only marginally attested in spoken languages is the digital system that we find in Indo-Pakistani Sign Language for numerals up to 999. It is possible in spoken languages to use digital numerals in specific contexts, e.g., for emphasis or clarification, saying something like I meant one five points, where there was a confusion between ' 15 ' and ' 50 '. However, the sign language digital numerals of the IPSL type are different in that this is the only way of signing numerals. Digital numerals of this kind also occur in other sign languages, but are more common for numerals between 10 and 20 
(as in Turkish Sign Language). To our knowledge, a numeral system where the digital strategy is the only option is not attested in spoken languages, so this is another interesting addition to the typological spectrum.

In addition, sign languages also use iconicity in several areas of cardinal numerals. The simplest form of iconicity is to use the corresponding number of extended fingers to indicate numerals. In spoken languages, numerals can only "talk about" hands and fingers, and spoken language forms may use the morphemes for 'hand' and 'finger' in lexemes. Hanke (2010: 72) mentions "neo-2 sums" (numerals made up of twice the same amount, as in ' $4+4$ ' for ' 8 ') in the sense of being "split up between two hands". Sign languages not only talk about hands and fingers, but due to their modality can directly demonstrate hands and fingers, making these forms very transparent. It has been suggested in Section 3.3 that this iconicity (a transparent, motivated link between form and meaning) may be one reason why we find a lot of variation in the numeral forms in some of the sign languages in our data.

Iconicity and motivation also take other forms in the data discussed here. Some forms of numerals are related to written numbers, such as the numeral NINE in IPSL (see Figure 1). In fact, this has a peculiar effect on the phonological system of some sign languages in that some phonological components (the equivalent to phonemes in spoken languages) occur only within the numeral system. In Zeshan (2000), the IPSL handshapes that only occur in numerals are part of a small class of "marginal handshapes" because of their restricted distribution. Such restricted handshapes also exist in other sign languages, such as the numeral SEVEN in American Sign Language, or SIX, EIGHT, and NINE in Ugandan Sign Language (Wallin et al. 2006), ${ }^{16}$ but to our knowledge, specific phonological forms that only occur in numerals are unattested in spoken languages.

As mentioned above, the numeral signs for ' 50 ' in MarSL, APSL, and LSChicana are based on shared iconicity, which is a phenomenon that is unlikely to occur across spoken language numerals. Finally, some numerals in the rural sign language data make iconic reference to money. The sign for ' 100 ' in LSChicana (Figure 7) derives from representing the horns of a deer because the 100-peso note in Mexico used to show a deer. This iconicity persists even today, although the currency is now different and no longer shows the picture of a deer. Another rural sign language, Kata Kolok in Bali, similarly has iconic connections between numeral signs and currency notes (de Vos 2012).

16. The Ugandan Sign Language numerals are iconic representations of written numbers, while the ASL numeral derives from manual counting on the fingers of one hand: in SIX, the thumb touches the little finger, in SEVEN, the thumb touches the ring finger, and so forth (see http://lifeprint.com/as1101/pages-signs/n/numbers.htm; accessed 17 April 2013). 
Interestingly, none of the rural sign languages in our data makes any use of writing as a source of iconic numeral signs (with a possible exception of ' 0 ', which we have not looked into at this stage). This is quite common in urban sign languages; in IPSL, several digits are derived from written numbers (Figure 1), and the numeral signs ' 6 ' to ' 9 ' in Turkish Sign Language derive from Arabic written numbers because the history of the language dates back to the time when Ottoman Turkish was written in Arabic script (Zeshan 2003). In rural sign languages, the deaf signers are typically illiterate and do not attend schools, which makes it less surprising that they may not link written numbers with numeral signs.

It is too early to say whether the presence or absence of formal education entails a consistent correlation across a larger sample of sign languages that would relate the form of numeral signs to the social environment of their users. On the contrary, our data show some striking evidence to suggest that numeral systems do not reflect local culture in a straightforward way. This is because there are striking mismatches between signed and spoken languages used in the same community. For instance, as mentioned in Section 3.2, the MarSL numerals bear no resemblance to the numeral systems used in any of the surrounding spoken languages. Moreover, all rural sign languages considered here have lexicalised certain numerals as monomorphemic forms that differ from the lexicalisation patterns in the surrounding spoken language(s). APSL has lexicalised ' 50 ' as a separate sign, whereas in the co-existing spoken language Urdu, the word for ' 50 ' (pachas) is related to the word for ' 5 ' (pãch). Conversely, spoken Balinese has a monomorphemic word for '50' (séket), but the co-existing rural sign language Kata Kolok has no such sign and instead uses five repetitions of ' 10 '. There is clearly no straightforward mapping between the signed and the spoken languages in the numeral systems of these communities, nor between the rural sign languages and the urban sign languages in the same wider region (e.g., LSChicana and Mexican Sign Language). Such observations offer an interesting window into the question of how the sociocultural environment correlates with linguistic features, because the same environment is shared by both the rural sign languages and their spoken counterparts, but many of the linguistic features are very different in the signed and the spoken languages.

While the sign languages discussed here have some structures that are missing in spoken languages, conversely some patterns in cardinal numerals are common in spoken languages, but not found in sign languages, possibly due to the much smaller data set for the latter. For instance, a wider range of numeral bases are attested in spoken languages compared to sign languages, and several types of systems (body part counting, restricted systems) are unattested in sign languages. Moreover, spoken languages have many instances of sequential morphology in cardinal numerals, as exemplified in the examples in Section 1.2. By contrast, there are no instances of sequential morphology in any of the 
sign languages here, and indeed, sequential morphology is quite uncommon in sign languages overall. Numerals in spoken languages often include morphemes meaning 'and' or 'with' (cf. the German example vier-und-zwanzig in Section 1.2). Again, such constructions are unattested in sign languages. Some more general conclusions from these patterns are drawn in Section 5.

\section{Conclusion: Towards a cross-modal typology of numeral systems}

This article has revealed some crosslinguistically rare sign language structures in three unrelated sign languages of small-scale rural communities. In so doing, we have demonstrated that in the domain of cardinal numerals, sign languages have a much greater degree of typological variation than previously recognised, and that both modalities need to be considered in order to put this variation properly into perspective. We can then begin to describe the patterns of both intra-modal variation (i.e., across different sign languages) and intermodal variation (i.e., between signed and spoken languages). This not only allows us to understand the significance of novel sign language data in an appropriately broad context, but also demonstrates that the crosslinguistic patterns of a grammatical domain cannot be fully understood until we have considered a wide variety of diverse languages from both modalities, signed and spoken. As sign language data have previously been largely absent from the "radar" of spoken language typology, a systematic approach to cross-modal typology has intrinsic value for future typological studies.

This article is a small case study showing why such a cross-modal approach with a substantial range of languages from both modalities would be both feasible and necessary. At present, this is not possible due to the absence of systematic typological data on numerals across sign languages. However, other studies in sign language typology (Zeshan 2004a, b; Zeshan (ed.) 2006; Zeshan \& Perniss (eds.) 2008) have already demonstrated a range of methods for working on such typological sign language data in other grammatical domains, and there is no reason why this could not be done for the domain of numerals. Undoubtedly, this will enable us to move towards a better cross-modal understanding of the typology of cardinal numerals in two respects, both of which are foreshadowed in the present article: (i) an empirically substantiated recognition that sign languages show considerable crosslinguistic variation; (ii) an understanding of patterns of variation that cut across modalities, with evidence of both modality-specific and cross-modal patterns.

What we lack at present is an explicit methodological approach to crossmodal typological studies. This raises some interesting questions, not only about the availability of sign language data, but also in terms of its comparability with spoken language data. For instance, do we need to think separately about those numeral signs that iconically reflect written numbers, since this 
strategy is by definition not available to spoken languages? One could argue that for this reason, these signs need to be excluded from cross-modal typological comparison, being in some sense peripheral to the linguistic system. Conversely, it could be argued that these signs are an integral part of numeral systems and in fact constitute a particularly relevant and interesting type of modality effect that must be accounted for in cross-modal typology. In this article, we have adopted the latter view. Similarly, should cross-modal comparisons be limited to the spoken words of spoken languages, or should conventional gestures, of which there are many in the domain of numerals, also be included? If so, to what extent are such data available from various spoken languages? This is an aspect we have not addressed in this article. Finally, many sign languages seem to show considerable variability in their cardinal numeral systems, possibly due to the role of iconicity or to sociolinguistic factors such as the propagation of sign language through schools for the deaf. If the level of variability turns out to be much greater in sign languages than in spoken languages, this may raise further methodological issues in terms of how much variability to include in a cross-modal study and in what way.

Eventually, a systematic approach to cross-modal typology will allow us to move to a sophisticated understanding of patterns of variation in both modalities, signed and spoken. Over time, if cross-modal typological work is applied to a larger number of domains, this may have profound implications for linguistic typology, conceptually, methodologically, and theoretically.

Received: 15 June 2012

University of Central Lancashire

Revised: 24 July 2013

Correspondence address: International Institute for Sign Languages and Deaf Studies (iSLanDS), HA120, University of Central Lancashire, Preston PR1 2HE, Lancashire, United Kingdom; e-mail: uzeshan@uclan.ac.uk

Acknowledgements: This research has been funded by the UK Arts and Humanities Research Council (AHRC) under the EuroBABEL programme of the European Science Foundation's EUROCORES scheme (project "Endangered Sign Languages in Village Communities", grant number $\mathrm{AH} / \mathrm{H} 500235 / 1$ ). We are very grateful to the participants in the three communities of Chican, Alipur, and Mardin for generously sharing with us their unique sign languages and cultural heritage. Hasan Dikyuva offers his particular thanks to Hasret Dilsiz, Sükrü Dilsiz, and the rest of the Mardin signers for their immense contribution to the workshops, which were enjoyable, memorable, and illuminating. Cesar Ernesto Escobedo Delgado wishes to thank two hearing interpreters, Audomaro Colli and Simon Colli, who translated between written Spanish and Chican Sign Language, and written Mayan and Spanish. He also expresses his gratitude to the deaf Chican villagers for providing essential background information about Mayan cultural life. Sibaji Panda would like to thank the numerous consultants in the Alipur community who have contributed to the research. We are grateful to David Gil for helpful comments on an earlier version of this article.

Abbreviations: APSL Alipur Sign Language; IPSL Indo-Pakistani Sign Language; LSChicana Chican Sign Language; LSM Mexican Sign Language; MarSL Mardin Sign Language; TID Turkish Sign Language. 
Transcription conventions:

On the line denoting manual signals:

$\mathrm{XXX}-\mathrm{XXX} \quad$ single sign with multi-word English gloss

SIGN^SIGN sequential compound

SIGN\#SIGN simultaneous morphology/simultaneous articulation of two signs

SIGN++ repetition of a sign

$\mathrm{xxx}++\quad$ repetition of a non-manual action

On the line denoting the nonmanual signals:

- top topicalisation

nod head nod

\section{References}

AYJNIHH \& Ulrike Zeshan. 2001. Basic course in Indian Sign Language. Mumbai: Ali Yavar Jung National Institute for the Hearing Handicapped (AYJNIHH).

Baker-Shenk, Charlotte \& Dennis Cokely. 1991. American Sign Language: A teacher's resource text on grammar and culture. Washington, DC: Gallaudet University Press.

Barriga Puente, Francisco. 1998. Los sistemas de numeración indoamericanos: Un enfoque areotipológico. Ciudad de México: Universidad Nacional Autónoma de México.

Chinchor, Nancy Ann. 1982. Morphological theory and numeral incorporation in American Sign Language. Providence, RI: Brown University doctoral dissertation.

Comrie, Bernard. 1997. Some problems in the theory and typology of numeral systems. In Bohumil Palek (ed.), Proceedings of LP' 96. Typology: Prototypes, item orderings and universals, 4156. Praha: Charles University Press.

Comrie, Bernard. 2005a. Numeral bases. In Haspelmath et al. (eds.) 2005, 530-533.

Comrie, Bernard. 2005b. Endangered numeral systems. In Jan Wohlgemuth \& Tyko Dirksmeyer (eds.), Bedrohte Vielfalt: Aspekte des Sprach(en)tods, 203-230. Berlin: Weißensee Verlag.

de Vos, Connie. 2012. Sign-spatiality in Kata Kolok: How a village sign language inscribes its signing space. Nijmegen: Max Planck Institute for Psycholinguistics doctoral dissertation.

de Vos, Connie \& Ulrike Zeshan. 2012. Introduction: Demographic, sociocultural, and linguistic variation across rural signing communities. In Zeshan \& de Vos (eds.) 2012, 2-23.

Dikyuva, Hasan \& Hasret Dilsiz. 2010. Mardin Sign Language. In Panda (ed.) 2010.

Dikyuva, Hasan \& Hasret Dilsiz. 2011. Endangered Languages Documentation Programme: Mardin Sign Language in Turkey. Paper presented at SIGN5 conference, Gazi Üniversitesi, Ankara, 21-23 October 2011.

Dikyuva, Hasan, Cesar Ernesto Escobedo Delgado, Sibaji Panda \& Ulrike Zeshan. 2012. Working with village sign language communities - deaf fieldwork researchers in professional dialogue. In Zeshan \& de Vos (eds.) 2012, 313-344.

Dikyuva, Hasan \& Ulrike Zeshan. 2008. Türk Işaret Dili - Birinci düzey. [Turkish Sign Language - Level One.] Nijmegen: Ishara Press.

Du Bois, John W.. 1978. Mayan Sign Language: Ethnography of nonverbal communication. Paper presented at the 77th annual meeting of the American Anthropological Association, Los Angeles.

Escobedo Delgado, Cesar Ernesto. 2010. Culture and sign language in a Mexican Mayan Deaf community. In Panda (ed.) 2010.

Finnish Association of the Deaf. 2003. Suomalainen viittomakielen verkkosanakirja. [Finnish Sign Language online dictionary.] http://suvi.viittomat.net/ (accessed 17 April 2013)

Fischer, Susan. 1996. By the numbers: Language-internal evidence for creolization. In William Edmondson \& Ronnie B. Wilbur (eds.), International review of sign linguistics, Vol. 1, 1-22. Mahwah, NJ: Erlbaum

Fuentes, Mariana \& Liliana Tolchinsky. 2004. The subsystem of numerals in Catalan Sign Language: Description and examples from a psycholinguistic study. Sign Language Studies 5. 94-117. 
Fuentes, Mariana, María Ignacia Massone, María del Pilar Fernández-Viader \& Alejandro Makotrinsky. 2010. Numeral-incorporating roots in numeral systems: A comparative analysis of two sign languages. Sign Language Studies 11. 55-75.

Gil, David. 2005. Distributive numerals. In Haspelmath et al. (eds.) 2005, 222-225.

Greenberg, Joseph H. 1978. Generalizations about numeral systems. In Joseph H. Greenberg (ed.), Universals of human language, Vol. 3: Word structure, 249-297. Stanford, CA: Stanford University Press.

Groce, Nora Ellen. 1985. Everyone here spoke sign language: Hereditary deafness on Martha's Vineyard. Cambridge, MA: Harvard University Press.

Hanke, Thomas. 2010. Additional rarities in the typology of numerals. In Jan Wohlgemuth \& Michael Cysouw (eds.), Rethinking universals: How rarities affect linguistic theory, 61-89. Berlin: De Gruyter.

Haspelmath, Martin, Matthew S. Dryer, David Gil \& Bernard Comrie (eds.). 2005. The world atlas of language structures. Oxford: Oxford University Press.

Hendriks, Bernadet \& Ulrike Zeshan. 2009. Sign languages in the Arab World. In Kees Versteegh, Mushira Eid, Alaa Elgibali, Manfred Woidich \& Andrzej Zaborski (eds.), Encyclopedia of Arabic language and linguistics, 222-235. Leiden: Brill.

Hurford, James R. 1975. The linguistic theory of numerals. Cambridge: Cambridge University Press.

Hurford, James R. 1987. Language and number: The emergence of a cognitive system. Oxford: Blackwell.

Hymes, Virginia Dosch. 1955. Athapascan numeral systems. International Journal of American Linguistics 21. 6-45.

Ichida, Yashiro. 2005. Nihonsyuwa no oninrontosuusitaikei. [Phonology of the Japanese Sign Language number system.] Sign Language Communication Research 57. 9-17.

Johnson, Robert E. 1991. Sign language, culture and community in a traditional Yucatec Maya village. Sign Language Studies 73. 461-474.

Johnston, Trevor, Adam Schembri, Robert Adam, Jemina Napier \& Darlene Thornton. 2005. Auslan Signbank. Online resource. http://www.auslan.org.au/ (accessed 17 April 2013)

Kisch, Shifra. 2008. "Deaf discourse": The social construction of deafness in a Bedouin community. Medical Anthropology: Cross-Cultural Studies in Health and Illness 27. 283-313.

Ktejik, Mish. 2013. Numeral incorporation in Japanese Sign Language. Sign Language Studies 13. 186-209.

Lane, Harlan. 1992. The mask of benevolence. New York: Knopf.

Lane, Harlan, Richard C. Pillard \& Mary French. 2000. Origins of the American deaf-world: Assimilating and differentiating societies and their relation to genetic patterning. Sign Language Studies 1. 17-44.

Lanesman, Sara. 2012. Algerian Jewish Sign Language: Its emergence and survival. Preston: University of Central Lancashire MA thesis.

Le Guen, Olivier. 2012. An exploration in the domain of time: From Yucatec Maya time gestures to Yucatec Maya Sign Language time signs. In Zeshan \& de Vos (eds.) 2012, 209-249.

Lucas, Ceil (ed.). 2001. The sociolinguistics of sign languages. Cambridge: Cambridge University Press.

Marsaja, I Gede. 2008. Desa Kolok: A deaf village and its sign language in Bali, Indonesia. Nijmegen: Ishara Press.

Massone, Maria Ignacia \& Robert E. Johnson. 1991. Numbers and numeral classifier suffixes in Argentine Sign Language. In Equality and self-reliance: Proceedings of the XI World Congress of the World Federation of the Deaf, Japan, 2-11 July, 743-762. Tokyo: Japanese Federation of the Deaf.

McKee, David, Rachel McKee \& George Major. 2011. Numeral variation in New Zealand Sign Language. Sign Language Studies 12. 72-97. 
Meir, Irit, Wendy Sandler, Carol Padden \& Mark Aronoff. 2010. Emerging sign languages. In Marc Marschark \& Patricia Elizabeth Spencer (eds.), Oxford handbook of deaf studies, language and education, Vol. 2, 267-280. Oxford: Oxford University Press.

Mori, Soya. 2005. Nihonsyuwa no 1 kara 2 ketanokazumadenosuusi. [Japanese Sign Language numerals from 1 to 99.] Sign Language Communication Research 57. 3-7.

Nederlands Gebarencentrum. 2010. Gebarenwoordenboek. [Dutch Sign Language dictionary.] Online resource. $h t t p: / / w w w . g e b a r e n c e n t r u m . n l / w o o r d e n b o e k . a s p ? c o l o r=y \& i d r e l e a s e=31 \quad$ (accessed 17 April 2013)

Nonaka, Angela. 2009. Estimating size, scope, and membership of the speech/sign communities of undocumented indigenous/ village sign languages: The Ban Khor case study. Language \& Communication 29. 210-228.

Nyst, Victoria. 2007. A descriptive analysis of Adamorobe Sign Language (Ghana) (LOT Dissertation Series 151). Utrecht: LOT. http://www.lotpublications.nl/publish/articles/002193/ bookpart.pdf

Padden, Carol \& Tom Humphries. 2006. Inside deaf culture. Cambridge, MA: Harvard University Press.

Panda, Sibaji. 2010. Minority and village sign languages in India: Research priorities, methodologies and future direction. In Panda (ed.) 2010.

Panda, Sibaji. 2011. Literacy development in Alipur: A village sign language community in India. Paper presented at SIGN5 conference, Gazi Üniversitsi, Ankara, 21-23 October.

Panda, Sibaji (ed.). 2010. Sign languages in village communities (Ishara Signed Publications 2). DVD. Nijmegen: Ishara Press.

Perniss, Pamela \& Ulrike Zeshan. 2008. Possessive and existential constructions in Kata Kolok. In Ulrike Zeshan \& Pamela Perniss (eds.), Possessive and existential constructions in sign languages, 125-149. Nijmegen: Ishara Press.

Sandler, Wendy, Irit Meir, Carol A. Padden \& Mark Aronoff. 2005. The emergence of grammar: Systematic structure in a new language. Proceedings of the National Academy of Sciences 102. 2661-2665.

Shuman, Malcolm K. 1980. The sound of silence in Nohya: A preliminary account of sign language use by the deaf in a Maya community in Yucatan, Mexico. Language Sciences 2. 144-173.

Shuman, Malcolm K. \& Mary Margaret Cherry-Shuman. 1981. A brief annotated sign list of Yucatec Maya Sign Language. Language Sciences 3. 124-185.

Skinner, Robert. 2007. A typological analysis of British Sign Language number variations. London: Birkbeck College, University of London, MA thesis.

Suwanarat, Manfa, Anucha Ratanasint, Vilaiporn Rungsrithong \& Lloyd Anderson. 1990. The Thai Sign Language dictionary. Revised edn. Bangkok: The National Association of the Deaf in Thailand.

Tang, Gladys. 2007. Hong Kong Sign Language: A trilingual dictionary with linguistic descriptions. Hong Kong: Chinese University Press.

Tree, Erich Fox. 2009. Meemul Tziij: An indigenous sign language complex of Mesoamerica. Sign Language Studies 9. 324-366.

van Cleve, John V. 1987. The Gallaudet encyclopedia of deaf people and deafness. New York: McGraw Hill.

von Mengden, Ferdinand. 2010. Cardinal numerals: Old English from a cross-linguistic perspective. Berlin: Mouton de Gruyter.

Wallin, Lars, Dorothy Lule, Sam Lutalo-Kiingi \& Bonnie Busingye. 2006. Uganda Sign Language dictionary. Kampala: Sign Language Project, Faculty of Special Needs Education, Kyambogo University.

Williamson, Kay (ed.). 1973. Benue-Congo comparative wordlist, Volume 2. Ibadan: West African Linguistic Society. 
Yang, Junhui (forthcoming). Numeral signs and compounding in Chinese Sign Language (CSL). In Ulrike Zeshan \& Keiko Sagara (eds.), Semantic fields in sign languages: Colour, kinship and quantification. Berlin: De Gruyter Mouton; Nijmegen: Ishara Press.

Zeshan, Ulrike. 2000. Sign language in Indo-Pakistan: A description of a signed language. Amsterdam: Benjamins.

Zeshan, Ulrike. 2003. Aspects of Türk İşaret Dili (Turkish Sign Language). Sign Language and Linguistics 6. 43-75.

Zeshan, Ulrike. 2004a. Hand, head and face: Negative constructions in sign languages. Linguistic Typology 8. 1-58.

Zeshan, Ulrike. 2004b. Interrogative constructions in signed languages: Cross-linguistic perspectives. Language 80. 7-39.

Zeshan, Ulrike. 2010. Village sign languages: A commentary. In Gaurav Mathur \& Donna Jo Napoli (eds.), Deaf around the world, 221-230. Oxford: Oxford University Press.

Zeshan, Ulrike (ed.). 2006. Interrogative and negative constructions in sign languages. Nijmegen: Ishara Press.

Zeshan, Ulrike \& Connie de Vos (eds.). 2012. Sign languages in village communities: Anthropological and linguistic insights. Berlin: De Gruyter Mouton; Nijmegen: Ishara Press.

Zeshan, Ulrike \& Pamela Perniss (eds.). 2008. Possessive and existential constructions in sign languages. Nijmegen: Ishara Press. 